\title{
PÓS-MODERNIDADE E A FICÇÃO BRASILEIRA DOS ANOS 70 E 80
}

\author{
POR
}

\author{
Bobby J. ChamberLain \\ University of Pittsburgh
}

\begin{abstract}
Se é verdade que não há ruptura com a modernidade, nem em sua dimensão social nem em sua dimensão cultural, é também verdade que existe uma clara consciência de ruptura (...) À consciência pós-moderna não corresponde uma realidade pós-moderna" [Sérgio Paulo Rouanet, "A verdade e a ilusão do pós-moderno", Revista do Brasil 2, 5 (1986), 49].
\end{abstract}

Em vez de uma "poética", talvez se trate, pois, de uma "problemática": um conjunto de problemas e questões básicas que foram criadas pelos diversos discursos do pós-modernismo, questões essas que não eram assim tão problemáticas antes mas que agora o são com certeza [Linda Hutcheon, A Poetics of Postmodernism: History, Theory, Fiction (New Yorke Londres: Routledge, 1988), 224].

I. A questão da pós-modernidade 1 -da sua existência, características, aplicabilidade e cronologia - tem sido, nos últimos anos, um dos temas mais discutidos e controvertidos no discurso crítico-teórico da literatura ocidental. Scholars os mais diversos, tais como Lyotard, Jameson, Hassan, Merquior, Hutcheon, e Eagleton, têm-se debruçado sobre o assunto. Já se gastou muita tinta com a descrição e identificação do "bicho" nas suas múltiplas formas e manifestações, tendo-se ocupado sobretudo com a delineação dos supostos contrastes deste com o antecessor imediato, a chamada era moderna. Produziuse, de fato, uma espécie de "graforréia" cheia de descritores com prefixos como des-, in-, anti- e pós- a fim de se diferenciar o etos literário vigente da poética modernista anterior termos como desconstrução, descentramento, descontinuidade, indeterminação, antitotalização e a própria pós-modernidade, entre outros. ${ }^{2}$ Mas, seja pela enormidade $\mathrm{e}$

\footnotetext{
' Não nos escapam os diversos problemas inerentes aos termos pós-moderno, pós-modernismo e pósmodernidade, tanto no contexto brasileiro como internacionalmente. No entanto, para os efeitos do presente trabalho, empregaremos as três palavras de maneira sinônima.

${ }^{2}$ Veja-se, a esse respeito, Hutcheon (3).
} 
diversidade do fenômeno, pela sua proximidade cronológica ou por outros motivos, ainda não se chegou a nenhum consenso sobre a sua especificidade nem mesmo a sua verdadeira existência como paradigma literário e cultural.

No Brasil, país periférico no esquema ocidental global, o debate, como seria de esperar, tem girado não só em torno dos assuntos de praxe identificados no pós-modernismo das sociedades metropolitanas como também sobre questões relacionadas com os eventos políticos nacionais das últimas três décadas, assim como a sua condição de país dependente, a própria perifericidade brasileira em si. Além de Merquior, outros críticos e teóricos brasileiros como Süssekind, Santiago e Rouanet têm participado de tal debate, nem sempre se concentrando, porém, na pós-modernidade enquanto fenômeno nacional. É de notar, contudo, que há nele muitas das mesmas dificuldades, dúvidas e desacordos que têm caracterizado tais discussões nos países mais desenvolvidos economicamente. $O$ que não há de surpreender, em vista da imprecisão fundamental com a qual o conceito tem sido tratado nos seus países de origem.

Pretendemos, nos parágrafos que se seguem, examinar algumas das características atribuídas com mais freqüência à pós-modernidade em relação à sua aplicabilidade à ficção brasileira das décadas de 70 e 80 . Para tanto, vamos repisar, em primeiro lugar, algumas das teorias mais propaladas da noção de pós-modernidade, tanto não-brasileiras quanto brasileiras. Logo, passaremos a considerar alguns dos romances e livros de contos publicados no Brasil nos últimos vinte anos à luz de tais formulações, dando relevo especial às características que nos parecerem as mais relevantes. Esperamos, destarte, contribuir não só para o maior esclarecimento do conceito de pós-modernidade em si como para a maior integração do fenômeno brasileiro no contexto internacional, amiúde destituído de outras vozes.

II. "Em grande parte, o pós-modernismo literário foi uma invenção de críticos", afirma Rouanet, em artigo publicado em 1986 num número especial da Revista do Brasil (41). Um dos primeiros a teorizar o pós-moderno na literatura é Ihab Hassan, cuja noção do fenômeno consiste inicialmente (c.1970) na percepção de um impulso antinômico, anárquico, calcado numa "vontade de desfazimento," ou "will to unmaking" (Hassan, The Dismemberment of Orpheus). Já em 1980, porém, Hassan parece ter incorporado ao conceito, originalmente apropriado do campo da arquitetura, grande parte da ideologia estruturalista e pósestruturalista daépoca, incluindo nele outrossim a preferência pela disjunção, pela abertura, pelo processo, pelo lúdico e pela fragmentação (Hassan, "The Question of Postmodernism"). A noção de descentramento, tão cara a Foucault e aos desconstrutivistas derrideanos, passa, um tanto ironicamente, a servir-lhe de base, abarcando não só os autores contemporâneos como, em alguns casos, os seus predecessores modernos mais excêntricos. Vislumbra-se, pois, o que se percebe como o começo de um novo paradigma estético, quem sabe uma nova episteme, para usar o termo de Foucault.

Uma das formulações mais influentes da pós-modernidade foi a feita por Jean-François Lyotard em 1979 num relatório intitulado La Condition postmoderne. "Simplificando ao extremo, eu defino pós-moderno como incredulidade nas metanarrativas", ele afirma na introdução (Lyotard, The Postmodern Condition xxiv). Para Lyotard, as "grandes narrativas" de emancipação e da unidade totalizante do saber humano - ou seja, as que arrogavam a si 
ciência absoluta e autoridade total— já perderam a sua legitimidade no mundo atual. E, no seu lugar, só permanecem as "pequenas narrativas", ou petits récits, instáveis "jogos lingüísticos", no dizer de Wittgenstein, sem pretensão alguma à soberania. Assim, a condição pós-moderna é caracterizada por uma crise epistemológica que não se pode resolver pela recorrência aos discursos mestres do passado - a doutrina religiosa, a ciência, o marxismo, a psicanálise - só sendo possível, no mundo de hoje em dia, não o consenso estável dos tempos idos e sim apenas os consensos provisórios, locais, assim como a busca constante da paralogia, da subversão do que ele chama de "ciência normal". Em ensaio publicado na revista Critique quatro anos depois ("Réponse à la question: qu'est-ce que le postmoderne?"), acrescenta: "O ecletismo é o grau zero da cultura geral contemporânea: a gente escuta o reggae, assiste os bangue-bangues, come a comida da McDonald's no almoço e a cozinha local no jantar, usa perfume parisiense em Tóquio e roupa rétro em Hong Kong; a ciência é matéria dos jogos de televisão" (Lyotard, "Answering the Question: What is Postmodernism?" 76). De fato, se a estética por excelência da atualidade é o kitsch, observa Lyotard, trata-se de um realismo do "vale tudo" calcado no poder aquisitivo do capital.

São essas algumas das mesmas características detectadas por Fredric Jameson no seu célebre ensaio "Postmodernism, or The Cultural Logic of Late Capitalism," publicado na New Left Review em 1984. A exemplo de Hassan e Lyotard, Jameson identifica a descontinuidade como um dos fundamentos mais importantes do pós-modernismo. Baseandose numa discussão não só da literatura e da arte contemporâneas como também da arquiteturapós-moderna, acrescenta todauma lista de características adicionais: o apagamento das fronteiras tradicionais entre a "alta cultura" e a "cultura popular" (ou de massas ou comercial); a planeza, ou falta de profundidade, uma qualidade de understatement ligada à diminuição do afeto; o desaparecimento do sujeito individual, da "mônada"; a abolição da historicidade, dando lugar ao pastiche, à modalidade da nostalgia; e, finalmente, um novo sublime pós-moderno alicerçado na replicação, no simulacro, na tecnologia, doutrina essa que se evidencia, por exemplo, na importância da televisão, do videoteipe, da copiadora e do computador. Na opinião de Jameson, um dos mais conceituados críticos marxistas dos Estados Unidos, em vez de sumirem totalmente, como alega Lyotard, os discursos mestres tradicionais ficaram submergidos no nosso pensamento, assim figurando no que ele denomina alhures o "inconsciente político" da atualidade (Jameson, prefácio de Lyotard, The Postmodern Condition). ${ }^{3}$

Um ponto de vista contrastante é sustentado por LindaHutcheon, no seu notável estudo A Poetics of Postmodernism, publicado em 1988. Para ela, uma das características mais salientes da estética pós-moderna é justamente a sua focalização da historicidade. Ao contrário da afirmação marxista feita por Jameson, Eagleton e outros de que há uma abolição da noção de historicidade na literatura pós-moderna, Hutcheon assevera que existe nessa literatura uma problematização da relação entre ficção e história. Trata-se, aliás, de uma literatura que coloca o discurso teórico em primeiro plano, questionando metaficcionalmente a própria autoridade. A literatura pós-moderna contesta, de fato, os discursos mestres da cultura humanista liberal como também põe em dúvida a separação humanista da arte e da

\footnotetext{
${ }^{3}$ Refiro-me, é claro, a Jameson, The Political Unconscious.
} 
vida. É uma literatura eminentemente paródica que também impugna a autoridade das instituições, a unidade do sujeito (do cogito), a coerência de tudo o que é tido como natural e inconsútil, assim como as fronteiras que dividem as artes, os gêneros, os discursos, as disciplinas, privilegiando antes o descontínuo, o local, o marginal. Diga-se de passagem que enquanto Jameson afirma a predominância do acrítico pastiche nos tempos que correm, Hutcheon prefere enfatizar a presença da paródia, assim dando maior realce à ruptura, à contestação do estatuído. O livro termina com uma consideração do estado ontológico do pós-modernismo. Será uma poética verdadeira ou antes uma simples problemática? As palavras da nossa segunda epígrafe parecem afirmar a segunda alternativa. "O pósmodernismo oferece "uma alterada constelação da arte e da vida-mundo", acrescenta a crítica, citando as palavras de Habermas, "mas o faz de uma maneira não segura e definida porém problemática e provisória" (Hutcheon, A Poetics of Postmodernism 229). Pois, antes de tudo, o estatuto pós-moderno é paradoxal, ambíguo e ambivalente, revelando na sua "dupla codificação" tanto uma contestação como uma cumplicidade.

Dos teóricos brasileiros a se ocuparem do assunto, um dos primeiros é José Guilherme Merquior. Em dois ensaios publicados em 1980 - "Em busca do pós-moderno" e "O significado do pós-modernismo" - ele enumera várias particularidades da escrita pósmoderna internacional: um hiperrealismo, a semiose metafórica e surreal do modernismo sendo substituído por uma semiose altamente metonímica; o eclipse do etos de vanguarda; o desejo de um novo iluminismo, de um racionalismo; e, final e um pouco ironicamente, a concepção lúdica da arte, iniciada ou, pelo menos, intensificada pela transição "neomodernista" de autores como Borges. Observe-se, entre parênteses, que a literatura brasileira, no parecer dele, descreve "um perfeito quiasmo relativamente ao caso europeu. Enquanto, na Europa, o modernismo se banhava numa semiose da escuridão, e o estilo neomodernista retornou à claridade, no Brasil, os grandes escritores modernos evitaram resolutamente a obscuridade-padrão do modernismo radical. Caberia a mestres neomodernos como Guimarães Rosa e Clarice Lispector comprometer as letras brasileiras com a "participação nas trevas"' (Merquior, O Fantasma Romântico e Outros Ensaios 38). Encarado sob esse ponto de vista, o quadro da literatura brasileira na atualidade seria misto se não um tanto confuso. No entanto, Merquior parece responder a interrogativa, embora indireta e parcialmente, no seu ensaio publicado no número especial da Revista do Brasil em 1986, notando que, pelo menos internacionalmente, a literatura pós-moderna apresenta as duas tendências antagônicas (Merquior, "Aranha e abelha: Para uma crítica da ideologia pós-moderna" 25). Afinal de contas, diz ele, "o pós modernismo ainda é em grande parte uma seqüência, antes que uma negação do modernismo (...) o pós-modernismo é um conceito em grande parte espúrio. Em segundo lugar, funciona como uma ideologia cultural cuja função é ocultar muito daquilo que poderia ser mais contestável nos falsos humanismos de nosso tempo" (26).

Outras vozes brasileiras também têm contribuído para o debate. Uma delas, a do supracitado Sérgio Paulo Rouanet, também nega a verdadeira ruptura com a estética modernista, como consta na primeira epígrafe acima, preferindo, a exemplo de Merquior, o termo "neo-moderno", se bem que o estenda para abarcar toda a gama contemporânea. Para ele, como para Habermas, "a modernidade não está extinta: (...) ela é um projeto incompleto" digno de ser completado (Rouanet, "A verdade e a ilusão do pós-moderno" 50). 
Em artigo publicado também em 1986 no mesmo número especial da Revista do Brasil dedicado à questão do pós-modernismo, o crítico e romancista Silviano Santiago analisa o narrador pós-moderno na obra do contistaEdilberto Coutinho, apoiando-se nas considerações tecidas por Benjamin sobre a obra de Leskov. Segundo o crítico, o narrador pós-moderno presente nos contos de Coutinho —os mencionados aparecem em Maracanã, Adeus (1980) ou na coletânea $O$ Jogo Terminado (1983) — desempenha, via de regra, o papel de um repórter, um jornalista a observar o mundo ao seu redor. Afirma:

O narrador se subtrai da ação narrada (...) e, ao se subtrair dela, cria um espaço para a ficção dramatizar a experiência de alguém que é observado e muitas vezes desprovido de palavra. Subtraindo-se à ação narrada pelo conto, o narrador identifica-se com um segundo observador - o leitor. (...) [E]les se definem como espectadores de uma ação alheia que os empolga, emociona, seduz, etc. (Santiago, "O narrador pós-moderno" 8)

Cria-se, em outras palavras, uma espécie de palco ou espetáculo, do qual narrador e leitor são meros espectadores, ambos a tirarem a sua própria parcela de prazer vicário do drama (reportagem, filme, telenovela) a se desenvolver diante dos seus olhos. O narrador pós-moderno seria, pois, como os narradores de Coutinho, não o indivíduo experiente ou compromissado, mas "apenas aquele que reproduz" (13) o que vê - imagens efêmeras na tela da vida. É de notar que Santiago faz uma distinção entre esse narrador pós-moderno, tão pobre em experiências pessoais como o seu próprio leitor, e os narradores memorialistas contemporâneos que se multiplicaram de maneira considerável no Brasil com o regresso de exilados políticos a partir da Lei de Anistia sancionada pelo governo Figueiredo em 1979. Se esses, já experientes, "fala[m] de si mesmo[s] enquanto personage[ns] menos experiente[s], extraindo da defasagem temporal e mesmo sentimental (...) a possiblidade de um bom conselho em cima dos equívocos cometidos por ele[s] mesmo[s] quando era[m] jove[ns]" (11), aquele ocupa-se antes da "pobreza da experiência, mas também da pobreza da palavra escrita enquanto processo de comunicação" (11).

Ora, é justamente desse mesmo período do drama político-cultural brasileiro que trata Flora Süssekind na sua importante colaboração no mesmo número da revista. O ensaio, intitulado "Ficção 80: Dobradiças \& vitrines", procura esclarecer as diferenças mais notáveis entre a ficção brasileira da década de 70 e a do decênio de 80 , concentrando-se nesta. A crítica faz referência, para tanto, a alguns dos romances e livros de contos brasileiros mais recentes, a fim de assinalar-lhes as características por ela julgadas mais marcantes e distintivas. Para ela, a saída dos censores das redações de jornal em junho de 1978 teve conseqüências decisivas para a ficção nacional, eliminando a necessidade da função parajornalística desempenhada por essa literatura nos anos imediatamente anteriores. "Desse modo", diz ela, "a vertente realista, tão forte na literatura brasileira, passou a adotar, na década de 80 , outros modelos literários, descartando contos-notícias e romancesreportagem, de um lado, e testemunhos e confissões, de outro" (82). Surge, por exemplo, o romance policial, como o Bufo \& Spallanzani de Rubem Fonseca (1985), assim como os romances Tocaia Grande, de Jorge Amado (1984), e Viva o Povo Brasileiro, de João Ubaldo Ribeiro (1984), que a crítica tacha de "literatura de fundação", ficção "que se crê História" (82). Se o primeiro apresenta uma solução de continuidade pelo entrecho estereotipado e fechado, ao mesmo tempo celebrando as exigências do mercado, os outros 
dois participam, na opinião dela, do que poderíamos denominar um certo essencialismo na medida em que procuram identificar no povo brasileiro um caráter imutável e coeso, isento de quaisquer contradições.

No entanto, Süssekind detecta na recente ficção nacional outras obras que, em vez de procurarem impor uma interpretação unívoca, ousam realçar as descontinuidades da vida e do discurso literário. Obras como Stella Manhattan, de Silviano Santiago (1985), ONome do Bispo, de Zulmira Ribeiro Tavares (1985), Maciste no inferno, de Valêncio Xavier (1983), Somos todos Assassinos, de Sebastião Nunes (1980) e Bandoleiros (1985) e o livro de contos OCego e a Dançarina (1981), ambos escritos por João Gilberto Noll. Tanto Stella Manhattan como O Nome do Bispo representam, para ela, exemplos da "contaminação" da ficção pelo ensaio, contaminação essa que, aliás, combina naquele com a técnica das personagens duplas, as "dobradiças", para salientarem a pluralidade fundamental do sujeito e do texto. Ao passo que livros como os de Xavier e Nunes se valem de justaposições das suas personagens com as dos filmes, de aproximações da sua linguagem com a da propaganda comercial. É de notar, aliás, que a mídia da "sociedade de consumo" (no dizer de Baudrillard) exerce uma forte influência sobre a maioria dos textos citados. Sirvam de exemplos, outrossim, as obras de Noll, nas quais o cinema, a televisão, o rádio, os outdoors e os vídeo-games não só constituem muitos dos cenários como também produzem imagens ou simulacros da realidade com as quais os protagonistas freqüentemente se identificam ou através das quais experimentam o mundo. Cabe observar, a esse respeito, que muitas das mesmas personagens são focalizadas amiúde através de vidros, de janelas, ou justapostas com vitrines, como a imitarem os próprios astros de cinema e televisão, seus ídolos de celulóide, cujas vidas se projetam na tela numa promiscuidade de fatos públicos e detalhes intimos. "[N]em a pompa memorialista, nem a heroização de um ego aventureiro e picaresco, como na prosa de 70" (86), explica ela, mas antes uma anulação do sujeito unitário, reduzido ao anonimato pela cultura de massas, a tecnologia e a ética do consumo.

Eis aí apenas algumas das caracterizações do pós-moderno propostas por críticos brasileiros e não-brasileiros nos anos recentes. Há outras, muitas outras, cuja exposição, infelizmente, fica além dos limites impostos pelo presente ensaio. ${ }^{4}$ A nossa amostragem é, sem dúvida, parcial e limitadora. Algumas opiniões beiram um minimalismo, omitindo importantes particularidades expressas por outras, às vezes ao ponto de serem redutivas. Outras concentram-se na pós-modernidade enquanto fenômeno metropolitano, prestando pouca ou nenhuma atenção para as manifestações registradas em países periféricos como o Brasil, ao passo que outras ainda focalizam tão-somente o contexto brasileiro, se não um único aspecto dele, em detrimento do quadro global. Parece-nos, contudo, que a discussão precedente pode servir de um excelente ponto de partida para a análise do pós-modernismo presente na ficção brasileira dos anos 70 e 80 . É disso, pois, que nos ocuparemos nos seguintes parágrafos, sempre levando em conta várias questões que nos parecem de especial pertinência. Por exemplo, como é que o pós-moderno na ficção brasileira difere do fenômeno europeu ou americano? E até que ponto o que passa pela pós-modernidade nas

\footnotetext{
${ }^{4}$ A bibliografia sobre o pós-modernismo na literatura já é extensa. Dentre as obras dedicadas ao assunto, destacam-se também as de Foster; Fokkema e Bertens; Santos; Carravetta e Spedicato; Subirats; e McHale.
} 
letras brasileiras é decorrente de circunstâncias especificamente nacionais, se bem que influenciadas pela globalização de tendências exógenas? $\mathrm{E}_{\mathrm{y}}$ afinal de contas, as características do pós-modernismo, quer nacionais, quer estrangeiras, chegam a constituir, como sugerem críticos como Hassan e Lyotard, uma poética, um paradigma no sentido kuhniano, coeso e singular, ou antes se trata de uma problemática de tendências diferentes e multifárias, às vezes contraditórias? Será ele apenas, ou mesmo em grande parte, uma simples invenção dos críticos, como querem alguns, uma continuação do modernismo mais do que uma ruptura com ele? E, à luz da sua freqüente ambivalência, ao que parece fundamental, não representará o pós-modernismo no Brasil tanto uma assimilação de como uma resistência à dominância de uma cultura metropolitana globalizante?

III. A nossa examinação de obras e autores específicos há de ser, por força, um exercício superficial, devido às limitações inerentes a um estudo como este. No entanto, já dispomos de algumas pistas procedentes das considerações de Santiago e Süssekind a respeito da produção romanesca e contística brasileira dos dois últimos decênios. A julgar pelas análises em questão, qualidades como a descontinuidade, a fragmentação do sujeito, o ecletismo, a homogeneização da "alta cultura" com a "cultura popular", a influência da tecnologia e da mídia massiva, a confusão de gêneros, a preocupação com o local, o emprego da teoria e de técnicas como auto-referencialidade e a metaficção são próprias das obras investigadas. Algumas remontam certamente aépocas e correntes anteriores-a reflexividade de um Machado de Assis, a integração da cultura popular numa obra como o Macunaima de Mário, o fraturamento vanguardista e o uso (e abuso) da colagem nos "romances" de Oswald. A mistura de gêneros é, de fato, um dos traços mais característicos dos românticos do século passado, tanto no Brasil como nos outros países, como o é também do próprio modernismo brasileiro, pelo menos nos dois casos antológicos acima referidos. A própria paródia (o pastiche?) aparece com frequeência ao longo da história da literatura brasileira, atingindo o ponto cume no modernismo. Mas nem por isso tais características deixam de ser também definidoras da ficção brasileira atual, sobretudo se as considerarmos em conjunto, ao lado das outras qualidades enumeradas, em sua maioria apenas típicas dos tempos que correm.

Além das obras de Edilberto Coutinho, Rubem Fonseca, Silviano Santiago, Zulmira Ribeiro Tavares, Valêncio Xavier, Sebastião Nunes e João Gilberto Noll, todas mencionadas pelos dois críticos citados, há muitíssimas outras que exemplificam cabalmente aquelas e outras características próprias da pós-modernidade, tanto nacional quanto internacional. Citemos, por exemplo, um autor como João Antônio (Leão de Chácara, 1975; Abraçado ao meu Rancor, 1986), cujas estórias "naturalistas" que versam, em sua maioria, sobre os baixos-fundos do Rio e de São Paulo, de fato, revelam o hiperrealismo mencionado por Merquior, o qual se manifesta também nos "romances-reportagem" dos anos 70 identificados por Süssekind em obra anterior. ${ }^{5}$ Há nele, outrossim, uma freqüente mistura da ficção com o documento histórico, assim embaralhando os estados ontológicos de uma maneira muito típica da ambivalente estética pós-moderna. Basta lembrar também o próprio Rubem

\footnotetext{
' Para uma discussão do fenômeno, veja-se Süssekind, Tal Brasil, qual Romance? A crítica referese especificamente a autores como José Louzeiro, Aguinaldo Silva e Renato Pompeu.
} 
Fonseca dos contos de Lúcia McCartney (1970) ou mesmo um contista como o Júlio César Monteiro Martins de Sabe quem dançou? (1978) para confirmar a ausência de afeto acusada por muitas dessas narrativas contemporâneas, principalmente as que se desenrolam em locais urbanos. Acrescente-se que há num e noutro uma forte dose da cultura popular, ou de massas, a imiscuir-se na vida das personagens freqüentemente apáticas e vazias. O leitor de romances como Zero, de Ignácio de Loyola Brandão (1974), Confissões de Ralfo, de Sérgio Sant'Anna (1975), Galvez, Imperador do Acre, de Márcio Souza (1976), Sangue de Coca-Cola, de Roberto Drummond (1981) e João Balalão, de Sérgio Tapajós (1981), há de identificar, sem hesitação, o cultivo do lúdico e do carnavalesco como um dos elementos mais importantes na composição deles, se bem que assuma formas diferentes em cada uma das obras. Se Zero e Sangue de Coca-Cola também participam livremente da justaposição de elementos da cultura popular e massiva, Confissões de Ralfo, Galvez e João Balalão exemplificam, de uma forma ou de outra, a linha picaresca que Süssekind identificou como sendo especialmente comum na década de 70 , isto sem mencionar as andanças kerouaquianas da protagonista de Um Telefone é Muito Pouco, de Sílvia Escorel (1983). A lista continua.

IV. Mas deixemos de impressionismos para penetrarmos um pouco mais alguns dos aspectos mais definidores da ficção brasileira dos últimos vinte anos. Deixando de lado, por enquanto, a questão da existência de um novo paradigma, concordemos que o pósmodernismo enquanto fenômeno brasileiro reflete muitas das características, conflitos e frustrações da situação política pela qual o país passou durante o período em questão, ao mesmo tempo destacando a condição periférica e dependente do Brasil na arena internacional, assim como a sua postura perante a própria pós-modernidade enquanto ideologia vinda de fora. Atente-se, por exemplo, não só em influências como a percebida por Süssekind em relação à mudança da ficção-reportagem de 70 para o romance de 80 ou no advento do memorialismo (não-ficção) ocasionado pela volta dos exilados como também em obras tais como Stella Manhattan, Sangue de Coca-Cola e Zero - se não também em livros como Galvez, Os Pareceres do Tempo, de Herberto Sales (1984) ou Em Liberdade, do próprio Silviano (1981) - pelo que têm de questionamento do arquivo histórico. Não é que discordemos da opinião de Jameson de que o pós-modernismo — ou pelo menos, um certo tipo de pós-modernismo-revela-se monológico e acrítico no que diz respeito ao tratamento da História. De fato, tal fenômeno verifica-se internacionalmente como também no contexto brasileiro, dando lugar a inúmeras versões nostálgicas, acrônicas, essencialistas e unívocas do passado remoto e recente. Cremos, porém — pace Jameson e alguns outros críticos marxistas - que existe também uma outra linha pós-moderna, fundamentada solidamente na problematização do arquivo histórico. Demais, parece-nos que essa tendência manifesta-se, a fortiori, na recente ficção brasileira, devido precisamente à forte influência do trauma histórico nacional dos últimos trinta anos. Sob esse prisma, não há, pois, a nosso ver, uma única pós-modernidade. Há várias.

Semelhante diversidade (ambivalência?) ocorre também no âmbito da autoridade narrativa, no tocante à soberania não só da História como das histórias. Existe, não há dúvida, um tipo de ficção dita pós-modernista ancorada em grande parte na univocidade do significante, na unitariedade e veracidade absoluta do sujeito narrador. É o caso, por exemplo, de muitas das obras de cunho "naturalista" que surgem na década de 70 , assim 
como das ficções monológicas e totalizantes produzidas pelos autores de segunda e terceira categoria. Isso sem falar nos chamados romances folhetinescos que abundam em qualquer época. (Serão mesmo pós-modernos?) Por outro lado, como já observamos, não faltam os romances e contos —os petits récits - contemporâneos que se auto-questionam, que se dobram sobre si mesmos, que recorrem, de uma forma ou de outra, à técnica da metaficção, assim se desmistificando e frisando a fatalidade da sua própria incapacidade para significar, para monopolizar a verdade. O emprego do ensaio em Stella Manhattan e outros romances, no fundo, não deixa de ser uma espécie de auto-referencialidade metaficcional. Idem, o discurso reflexivo da personagem-narrador de Bufo \& Spallanzani na medida em que se refere ao próprio ato de escrever. Em artigo que faz parte de um número da revista Hispania dedicado exclusivamente à língua e letras luso-brasileiras, Nélson H. Vieira cita obras tais como A Festa (1976) e A Face Horrivel (1986), de Ivan Ângelo; Stella Manhattan e Em Liberdade, de Santiago; Confissões de Ralfo e A Tragédia Brasileira (1987), de Sant'Anna; e Bufo \& Spallanzani e Vastas Emoções e Pensamentos Imperfeitos (1988), de Fonseca, como sendo dos mais notáveis exemplos da metanarrativa na literatura brasileira dos últimos anos. Em todos esses casos, explica ele, os autores se servem de técnicas metanarrativas, tais como "a autoconsciência textual, a ficção memorialista, narradores autoreferenciais, ironia reflexiva, metalinguagem e intertextualidade" (585), a fim de desmascararem a própria ficcionalidade e de contestarem todas as formas de hegemonia e autoridade sócio-políticas e literárias.

Também na questão do cultivo da paródia ou do pastiche, parece-nos que há uma coexistência de técnicas, dando-se freqüentemente uma hibridização dos recursos. Em apêndice do artigo "A permanência do discurso da tradição no modernismo", preparado para um curso intitulado "Tradição/Contradição", Silviano Santiago responde uma pergunta sobre a diferença entre um e outro, afirmando o seguinte:

[E]u não diria que o pastiche reverencia o passado, mas diria que o pastiche endossa o passado, ao contrário da paródia, que sempre ridiculariza o passado. (...) A paródia é mais e mais ruptura, o pastiche mais e mais imitação, mas gerando formas de transgressão que não são as canônicas da paródia. (Santiago, "A permanência do discurso da tradição no modernismo" 115,117 )

É de notar que o crítico faz menção da supracitada afirmação de Jameson de que ocorre no pós-moderno um abandono da paródia a favor do pastiche. Acrescenta, no entanto, que ele próprio se valeu da segunda técnica ao escrever o romance Em Liberdade (116-117), assim dando a entender que não se trata simplesmente de uma escolha por parte do autor entre uma alternativa contestatória do arquivo histórico, digna de ser utilizada (a paródia) e outra aistórica, conivente nas suas pretensões hegemônicas e que se deve evitar a todo custo (o pastiche).

O caráter eminentemente ambivalente do(s) pós-modernismo(s) insinua-se, a nosso ver, até mesmo na reação de muitos autores brasileiros à estética enquanto importação de uma cultura de massas globalizante. Se ideologias como a antropofagia oswaldiana e a teoria da dependência por um lado se queixam do influxo ininterrupto e acrítico de bens culturais oriundos de fora e freqüentemente de valor duvidoso -aliás, posicionamento 
louvável, a nosso ver- não falta, por outro lado, quem os aceite de braços abertos, mesmo alegando tê-lo feito sous rature, à derrideana, muitas vezes com apenas um mínimo de transformação dos códigos metropolitanos. À luz de semelhante assimilação, em que consiste, pois, o pós-modernismo brasileiro? Como é que difere fundamentalmente essa versão periférica do fenômeno que opera nos países da Europa ou nos Estados Unidos? Jameson, em artigo intitulado "Third-World Literature in the Era of Multinational Capitalism", publicado em Social Text em 1986, afirma a noção da existência de "alegorias nacionais" que fatalmente se manifestam em todos os textos de Terceiro Mundo. Reconhecendo os muitos problemas inerentes a tal asseveração, sobretudo os enumerados por Aijaz Ahmad no ensaio "Jameson's Rhetoric of Otherness and the "National Allegory", perguntamo-nos se não haverá, via de regra, em tais atitudes nacionais em face das importações culturais estrangeiras, sejam adversas ou favoráveis, representações do tradicional drama histórico brasileiro perante as influências das culturas hegemônicas. Não há dúvida de que umas reações, ou atitudes, seriam mais salutares que outras, no que se refere à sua afirmação da cultura nacional. Acresce que haveria também, em muitos dos casos em questão, uma mistura ambivalente das duas atitudes, aliás sem a mínima suspeita por parte de muitos dos autores das contradições inerentes a tais atitudes.

De resto, a pós-modernidade brasileira, quer literária e cultural, quer sócio-política, não pode se cifrar tão-somente em supostas reações às importações culturais metropolitanas. É, conforme já comprovamos acima, em muitos outros aspectos um fenômeno sui generis, decorrente de circunstâncias especificamente nacionais, independentes, em grande parte, das influências exógenas. Aliás, o cepticismo brasileiro para com os discursos oficiais e autoritários não precisava de um Derrida ou de um Foucault para tomar forma. Bastavam as inúmeras repressões e ofuscações perpetradas pelo regime militar pós-1964 para que o brasileiro se tornasse, nesse sentido, um ser pós-moderno. A Abertura, a Lei da Anistia, e o começo da "redemocratização", quer nas suas fases iniciais nos anos 80 (a vitória do Tancredo, a posse e o governo do Sarney), quer na "conjuntura atual" (o impeachment do Collor), têm exercido uma influência extremamente marcante na cultura e na literatura do país, sobretudo nas décadas de 60,70 e 80 . No entanto, nem por isso se deve pensar que se trate de um fenômeno unitário e inconsútil, mesmo no que diz respeito à literatura enquanto discurso de resistência. Pois, a pós-modernidade brasileira -repetimos com insistência- é, como a de outros países, antes de tudo, um discurso ambivalente.

V. É a essa luz, então, que deve ser lida a fíç̧ão brasileira dos últimos vinte anos. Tratase, em efeito, de um fenômeno multifário e contraditório, cuja explicação, mesmo do ponto de vista da estética pós-moderna, torna-se sumamente problemática. Constituirá um novo paradigma literário e cultural, como afirmam alguns críticos? Ou será, antes, fabrico da própria crítica literária ou cultural, uma mistura de elementos heteróclitos passível de ser explicada pela aplicação do estatuto modernista? Demais, pode-se construir uma poética do pós-moderno, quer brasileiro, quer não-brasileiro, ou torna-se necessário falarmos no plural, mesmo no que se refere às letras nacionais? Não há dúvida de que se percebe uma ruptura com o passado modernista, tanto no Brasil como em outros países. Não se trata apenas de uma problematização de estéticas anteriores. As opiniões dos supracitados teóricos e críticos vêm confirmar tal hipótese. Mas daí concluirmos que se trate de um novo 
paradigma literário e cultural suscetivel da formulação de uma poética própria, coesa e afirmativa, parece-nos, neste momento, ser uma asserção duvidosa.

\section{Obras Citadas}

Ahmad, Aijaż. "Jameson's Rhetoric of Otherness and the "National Allegory"'. Social Text 17 (1987): 3-25.

Carravetta, Peter, e Paolo Spedicato. Postmoderno e la Letteratura. Milão: Bompiani, 1984.

Fokkema, Douwe, e Hans Bertens, eds. Approaching Postmodernism. Amsterdã e Filadélfia: J. Benjamins, 1986.

Foster, Hal, ed. The Anti-Aesthetic: Essays on Postmodern Culture. Port Townsend, Washington: Bay Press, 1983.

Hassan, Ihab. The Dismemberment of Orpheus: Toward a Postmodern Literature. Nova Iorque: Oxford University Press, 1971.

. "The Question of Postmodernism". In Garvin, Harry R., ed. Bucknell Review: Romanticism, Modernism, Postmodernism. Lewisburg, Pennsylvania: Bucknell University Press, 1980.

Hutcheon, Linda. A Poetics of Postmodernism: History, Theory, Fiction. Nova Iorque e Londres: Routledge, 1988.

Jameson, Fredric. Prefácio ("Foreword") de Lyotard, The Postmodern Condition vi-xxi. . The Political Unconscious: Narrative As a Socially Symbolic Act. Ithaca, NY: Cornell University Press, 1983.

. "Postmodernism, or The Cultural Logic of Late Capitalism". New Left Review 146

(Julho-Agosto 1984): 53-92.

"Third-World Literature in the Era of Multinational Capitalism". Social Text 15 (Outono 1986): 65-88.

Lyotard, Jean-François. "Answering the Question: What Is Postmodernism?". Tradução

R. Durand. In Lyotard, The Postmodern Condition, 71-82.

. The Postmodern Condition: A Report on Knowledge. Tradução G. Bennington e

Brian Massumi. Minneapolis: University of Minnesota Press, 1984.

McHale, Brian. Postmodernist Fiction. Nova Iorque: Methuen, 1987.

Merquior, José Guilherme. "Aranha e abelha: Para uma crítica da ideologia pós-moderna". Revista do Brasil 2, 5 (1986): 22-27.

. "Em busca do pós-moderno". In O Fantasma Romântico e Outros Ensaios. Petrópolis: Vozes, 1980: 9-26.

- O Fantasma Romântico e Outros Ensaios. Petrópolis: Vozes, 1980.

. "O significado do pós-modernismo". O Fantasma Românticoe Outros Ensaios, 2741.

Revista do Brasil: Literatura Anos 80. Ed. Heloísa Buarque de Hollanda. 2, 5 (1986).

Rouanet, Sérgio Paulo. "A verdade e a ilusão do pós-moderno". Revista do Brasil 2, 5 (1986): 28-53.

Santiago, Silviano. "O narrador pós-moderno", Revista do Brasil 2, 5 (1986): 4-13. . "A permanência do discurso da tradição no modernismo". In Nas Malhas da Letra: Ensaios. São Paulo: Companhia das Letras, 1989: 94-123. 
Santos, Jair Ferreira dos. O que é o Pós-moderno. São Paulo: Brasiliense, 1986.

Subirats, Eduardo. Da Vanguarda ao Pós-modernismo. São Paulo: Nobel, 1986.

Süssekind, Flora. "Ficção 80: Dobradiças \& vitrines". Revista do Brasil 2, 5 (1986): 8289.

Tal Brasil, qual Romance? Rio de Janeiro: Achamié, 1984.

Vieira, Nelson H. "Metafiction and the Question of Authority in the Postmodern Novel from Brazil", Hispania 74 (September 1991): 584-593. 